Arab World English Journal (AWEJ) Volume 12. Number4 December 2021

DOI: https://dx.doi.org/10.24093/awej/vol12no4.22

Pp. $340-348$

\title{
The Necessity of Endowing EFL Learners with the Fifth Language Skill: A Key to a Successful Learning Experience
}

\author{
Fatma ZAGHAR \\ Department of English, Faculty of Foreign Languages \\ University of Oran 2 - Mohamed BEN AHMED - Oran, Algeria \\ Corresponding Author: tzafour@yahoo.com \\ El-Alia Wafaâ ZAGHAR \\ Department of English, Faculty of Foreign Languages \\ University of Oran 2 - Mohamed BEN AHMED - Oran, Algeria
}

Received: 9/30/2021

Accepted: 11/1/2021

Published: $12 / 15 / 2021$

\begin{abstract}
In this increasingly interconnected epoch, the teaching of English as a Foreign Language (EFL) along with culture that is considered as a fifth skill has become inevitable. Therefore, EFL teachers are impelled to introduce cultural instruction in their classes. They are then advised to combine the teaching of language skills with the foreign culture because it prepares their learners to behave successfully in intercultural encounters, gain solid cultural knowledge, overcome cultural obstacles, and promote their cultural awareness. The main questions addressed in this research focus on the inclusion of the cultural component in language subjects' syllabuses, and the type of teaching strategies that can ameliorate the status of cultural instruction. This study points out the key importance of implementing intercultural information in EFL contexts founded on a case study undertaken at the University of Oran 2 in Algeria. This paper targeted a group of Master II students by using an array of data collection means including a questionnaire given to the learners, an interview done with the teachers, and classroom observation sessions carried out by the researchers. The major aims of this work were to verify the learners' perceptions of cultural learning, and outfit students with core foundations of culture. The results demonstrated that the incorporated teaching techniques have enriched the students' cultural understanding and intensified their linguistic adeptnesses. It is suggested that these teaching initiatives can aid learners be compassionate, understandable, and tolerant human beings.

Keywords: Cultural awareness, EFL contexts, fifth language skill, Master students, teaching strategies
\end{abstract}

Cite as: ZAGHAR , F., \& ZAGHAR, E. W. (2021). The Necessity of Endowing EFL Learners with the Fifth Language Skill: A Key to a Successful Learning Experience. Arab World English Journal, 12 (4) 340-348. DOI: https://dx.doi.org/10.24093/awej/vol12no4.22 


\section{Introduction}

In the current-time progressively globalized climate, where modern instruments of communication can ensure that our learners can be acquainted with alien cultures with unprecedented ease, it is even more inescapable for EFL teachers to pique their students' interests to facts about gaining mastery of the target language along with its cultural norms and issues. Teaching culture as an integral ingredient of language learning boosts the learners' cultural awareness, broadens their horizons, and deepens their general knowledge. Intercultural language learning provides the requisite skills for students to assist them in the use of language in culturally aware manners. It also prepares them to manage and appreciate border crossing on multitudinous levels.

The principal premise of this work is to accentuate a pressing need for the incorporation of intercultural awareness in EFL milieux by propounding some instructional methods that repel violence and call for understanding and mutual respect.

\section{Background}

Language and Culture: Establishing the Ties

Understanding language affects the ways it is taught, and it impacts lesson planning and classroom pedagogies. Being a complex system practiced by people in their daily lives to express themselves, language has a dual function; it is both a communication tool and a culture vehicle. To speak a language implies having access to a culture; it is through language that a human being is identified as a member of a community, of a culture. It is approved that language serves as an essential window on the universe; it mirrors culture and allows its users to acquire aspects of the culture they carry. Language and culture are entwined; they are closely interrelated and vital to building a solid partnership. In the same vein, Ishihara and Cohen (2021) spotlight:

Learning a new language can be compared to joining a new community physically or metaphorically, and can be viewed not just as acquiring language form but also understanding social norms and cultural practices commonly shared in the second language (L2) community, which are not always explicitly stated or obvious to novice members or outsiders (p.1).

As a result, a good comprehension of the inextricable interrelationship and interdependence between language and culture altogether with a sound grasp of diverse cultures will lead to successful intercultural communication.

\section{What is Culture?}

Due to its complex quality, culture is a fuzzy and challenging concept that has manifold meanings and has been utilized in distinct discourses. Culture is viewed as a whole social heritage of man. It is an amount of knowledge that people have about a given society. This knowledge can be seen in diverse ways, and when translated into language teaching and learning means teaching a sum of information about what people think, believe, own, and do as members of a particular community.

The various definitions of culture attest its complicatedness as a human phenomenon. Specialists, for centuries, have not reached a consensual and standard interpretation; each perceived it from a particular angle. Some scholars describe it as a social fact and as a learned behavior, others view it as a system of symbols and meaning, and another category see it as a communication system. Culture is regarded as the carrier of people's values and thoughts and as 
being dynamic because it is subjected to changes; it is fluid rather than static. This suggests that culture is a system of communication through which people convey their feelings, beliefs and perceptions. Highlighting this eminent function, Samovar et al. (1981) point out:

Culture and communication are inseparable because culture not only dictates who talks with whom, about what, and how the communication proceeds, it also helps to determine how people encode messages, the meanings they have for messages, and the conditions and circumstances under which various messages may or may not be sent, noticed, or interpreted... culture... is the foundation of communication (p.24).

Accordingly, some definitions refer to culture as a symbolic system. Many anthropologists and linguists maintain that it is a system that comprises a range of symbols and meanings which are communicated through a linguistic system. Symbols are of great importance in making sense of culture and help in making up our communication mode. In this regard, Leeds-Hurwitz (1993) clarifies that culture is:

a set of systems or codes of symbols and meanings. 1) Culture is composed of symbols and other signs; these provide a structure for social actors, limiting possible choices to those culturally available. 2) These symbols and signs are the tools people use to convey meaning; these are the resource materials from which people choose to convey what meanings they wish. 3) These symbols and signs are combined into systems (or codes). 4) Researchers study particular texts in order to understand how the larger entity, culture, operates (p.17).

\section{Fundamental Components of Culture}

In this huge globe, there is a variety of cultures which are depicted as being unique and specific. All cultures contain special parts that are vital for the process of humans' existence and social interactions. In the area of foreign language education, it is recommended that the first thing to consider is the amount of difference between your own and the host culture in terms of the elements of culture (Paige \& al., 2020). Some of these elements are described as being observable, such as behaviors and practices, and the others as not observable, namely perceptions, attitudes, beliefs, values, etc. (see figure 1).

\section{Behaviors}

Behaviour is a word that refers to the way in which people comport themselves and react to the situations they confront on the basis of their gained beliefs and values. Consequently, productive, efficient, and healthy persons are able to shift roles as needed (e.g., from participant to leader, from employee to spouse) and understand the appropriate behaviors in each context (Cushner \& Brislin, 1996).

\section{Perceptions}

Perception means the capacity of obtaining knowledge and impressions by means of the senses and awareness. It is claimed that perception goes through three stages:

- Selection: it is the first step through which special information is amassed.

- Organization: at this phase, the information is structured in an understandable manner.

- Interpretation: in this final level, people assign meaning to data on the ground of their experiences. 


\section{Attitudes}

An attitude is defined as a psychological reaction to people, conditions and facts that has an impact on a person's behavior. It is also an association of one's opinions and emotions. Attitudes play a crucial role in governing different aspects of persons' character because they influence the way they discern and act towards many situations.

\section{Beliefs}

Beliefs have to do with the sum of viewpoints that people hold about the outside world. A belief represents a set of cultural facets that one inherits from his own community. Beliefs are determined by the individual's culture. As a consequence, cultural beliefs are shared by considerable members of a given culture.

\section{Values}

Values are the moral norms and beliefs that affect people's actions. They are essential to understand how culture functions and individuals use them to guide their thoughts and behaviours. Cushner and Brislin (1996) opine that:

People make judgements and draw conclusions about what is and what is not of value. These judgements give rise to certain presuppositions from which people act with little or no conscious awareness. These presuppositions learned during childhood, play a pervasive role in all areas of people's adult experiences (p.318-319).

This implies that values have an important effect on humans' ways of thinking and behaving. Moreover, they are the ground for one's conduct and motivation.

All these elements of culture can be expressed by human beings through the use of language, that is they are conveyed by it. This shows the close relationship between language and culture. In this respect, the authors highly recommend EFL teachers to include the foreign culture in their courses.

\section{The Cultural lceberg}

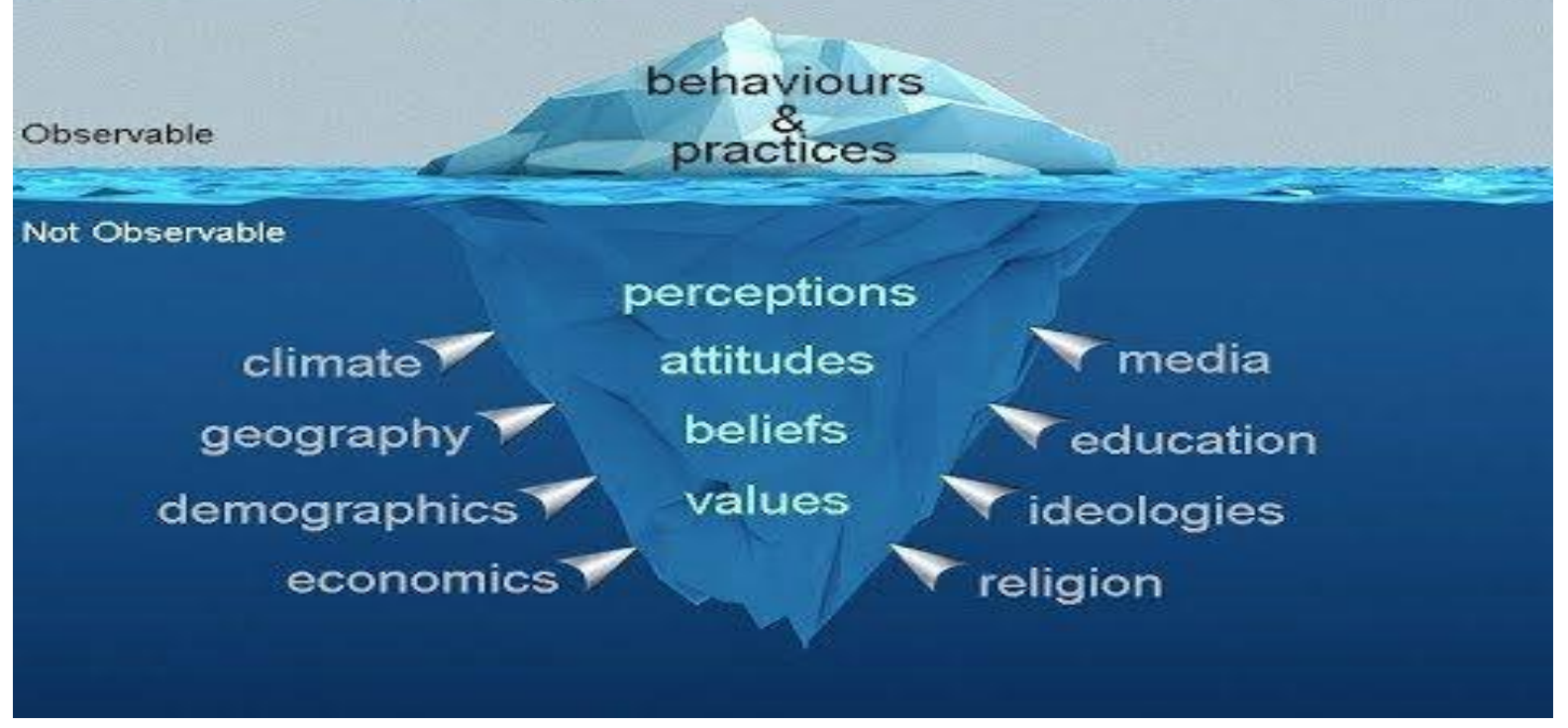

Figure 1. The Cultural Iceberg in 2021 (adapted from printerest.com) 


\section{Defining Interculturality}

Interculturality signifies the interaction and exchange between individuals from diverse cultural contexts, using language suitably in a manner that reflects awareness and ability to understand other cultures. Similarly, Barrett (2008) declares that interculturality is:

the capacity to experience cultural otherness and to use this experience to reflect on matters which are normally taken for granted within one's own culture and environment....in addition, interculturality involves using this heightened awareness of otherness to evaluate one's own everyday patterns of perception, thought, feeling and behaviour in order to develop greater self-knowledge and self-understanding (p.1)

Interculturality, therefore, surpasses having information about a dissimilar culture, it comprises learning to comprehend how one's culture shapes beliefs of oneself, of the world, and of human beings' bounds with others. To highlight the role of intercultural language learning in promoting the students' grasp of their language and culture as well as the recognition of other languages and cultures. Liddicoat et al. (2003) maintain:

Intercultural language learning involves developing with learners an understanding of their own language (s) and culture(s) in relation to an additional language and culture. It is a dialogue that allows for reaching a common ground for negotiation to take place, and where variable points of view are recognised, mediated, and accepted. Learners engaged in intercultural language learning develop a reflective stance towards language and culture, both specifically as instances of first, second, and additional languages and cultures, and generally as understandings of the variable ways in which language and culture exist in the world (p.46).

Additionally, teaching interculturality to language learners allows them to overcome cultural barriers because in terms of education for interculturality, the idea that the awareness and knowledge of other cultures can help us either reduce or remove stereotypes is strong (Dervin \& Simpson, 2021).

Intercultural language learning, hence enables learners to better comprehend their own and others' thoughts and experiences which will increase awareness of the self and of the others. As a result, it is highly appreciated to integrate this specific learning in English classes.

\section{Methodology}

The main research aims were to explore the students' thoughts about learning the alien culture and propose some teaching strategies that can improve the learners' language capacities and help them up their cultural awareness. Based on the research objectives, the following research questions were formulated:

RQ1. Is the cultural component included in language subjects' syllabuses?

RQ2. What type of teaching strategies can meliorate the status of this cultural instruction?

As possible answers, the following hypotheses were suggested:

H1. It seems that the cultural components are integrated in a limited way.

H2. A teaching built on the engagement of the learner in the teaching/learning process with the teacher's orientations may lead to a betterment of the teaching of cultural facets in EFL settings.

Participants and Procedures 
This academic study cited in this paper took place at the University of Oran 2 in Algeria. It targeted 95 Master II EFL students and 7 teachers in the department of English. To gather useful data, a questionnaire administered to the learners, an interview conducted with the teachers, in addition to the process of classroom observation, were utilized.

With regard to the basic aims, students' opinions were investigated through a questionnaire because this tool can be used to elicit teachers' and students' comments on a wide range of issues and information can be obtained from large numbers of respondents (Richards, 2005).

Being powerful data collection instruments, the interviews were carried out with the teachers because they allow for a more in-depth exploration of issues than is possible with a questionnaire (Richards, 2005).

To capture what happens in reality within the classroom, the process of classroom observation has been adopted as echoed by O'Leary (2020):

Schools and universities have come to rely on it as an important means of collecting evidence about what goes on in classrooms. This evidence has invariably been used to inform current conceptualizations of what makes for effective teaching and learning along with providing the basis on which judgements about the performance and competence of teachers are made (p.xii).

The examination of the use of cultural ingredients in Master II students' syllabi shows that these aspects are included in a very limited extent or sometimes totally absent from some courses. For this purpose, the researchers see that the organisation of seminars whose main topics accentuate culture and which will be devoted basically to these learners. These seminars will also try to involve the students in the learning process and encourage collaboration between them because this can help them enrich their cultural awareness and high-order thinking skills (Toyoda, 2016).

The proposed courses do contain pivotal themes, namely:

- Introduction to Culture

- Ethnocentrism

- Prejudice

- Culture Shock

- Cultural Awareness

The learners are asked to work in pairs or groups on these topics related to culture, they are required to carry out researches on them, then to give presentations on these topics. The emphasis will be put on:

- Cultural knowledge: This means the understanding of cultural differences.

- Cultural skills: This implies the ability to act and behave appropriately in a myriad of cultures.

These skills encompass mutual respect, tolerance, and dealing with conflicting situations.

\section{Major Findings}

- Learners' Questionnaire

The analysis of the learners' questionnaire shows that $74,73 \%$ of the informants declared that the inclusion of the cultural components in their language modules is moderate. $22,10 \%$ 
said that it is rare to deal with culture in their classes. Only 3,16\% perceived that culture is never integrated in their courses. When asked about their viewpoints about the intercultural activities that were implemented in their course, all of the respondents enunciated their deeper appreciation of the proposed teaching techniques. They reported that it has really helped them to gain a profound understanding of many key notions, and to engage effectively in the learning process.

\section{- Teachers' Interview}

The totality $100 \%$ of the interviewed teachers revealed that the amount of cultural ingredients incorporated in language subjects is really insufficient. Many of them stated that cultural teaching is an integral part in foreign language education, and thus it should be encouraged in all modules. $85,71 \%$ of the participants opined that cultural teaching needs to be revisited. They claimed that the teaching of culture can be improved through the incorporation of technology, because according to them digital resources will offer the students the possibility to get better acquainted with authentic materials, and to explore the target language and its culture in a profound way. As a result, the learners' language abilities and culture knowledge will be expanded and reinforced.

\section{- Classroom Observation}

Classroom observation sessions demonstrated that the students were really engaged in the learning process, they expressed a wide range of opinions, and discussion was promoted. Moreover, the researchers noted that the students prefer to learn in a dynamic and autonomous learning atmosphere.

\section{Discussion of the Findings}

The results revealed the following points:

1- The Need to Give more Importance to Foreign Culture Learning in Master Courses:

The analysis of the questionnaire indicated that the majority of students $(95,79 \%)$ expressed their strong desire to learn about alien cultures because they see that this learning can expand their knowledge and equip them with necessary abilities to take part in worldwide encounters. One of the participants declared that: being interculturally competent makes me feel confident even if I am abroad. Most of the learners insist on the fact that obtaining a sound cultural teaching is a valuable asset that:

- helps them understand their own culture to preserve their identity and their values.

- gives them the possibility to develop effective communication skills.

- allows them to overcome cultural barriers and avoid misunderstandings.

- helps them realise their personal growth.

2- An Increase of Intercultural Awareness:

From the teachers' interview, it was deduced that there was a real recognition by EFL teachers about the little or no inclusion of cultural material in English courses in general and Master's Lectures in particular which confirms our first hypothesis. Most of the teachers $(85,71 \%)$ expressed the real quest for integrating the teaching of culture in all classes. They maintained that bringing the foreign culture into the classroom can raise the learners' enthusiasm, enlarge their vocabulary, enhance their language competencies, and augment their intercultural awareness.

3- An Effective Involvement in the Learning Process: 
These strategies seemed to engage students in the learning process, and this confirms our second hypothesis. Through observation sessions, it was noticed that their focus and attention have been raised, since they were attracted by the information brought by their peers in the classrooms. This climate has encouraged discussion and produced higher quality effort among Master students. Their engagement has therefore been boosted, and their motivation was conspicuous.

4- Acquisition of Large Amounts of Oral and Written Input:

When observing these learners, it was inferred that out of these seminars, the students could acquire considerable notions of language capabilities including:

- Familiarity with technical words.

- Accuracy and fluency in writing.

- Conducting a debate.

- Learning how to develop a sense of analysis and criticism.

As a consequence, the analysis of the results demonstrated a good understanding of the proposed topics, an acquisition of useful information, and a better learning achievement.

\section{Conclusion}

This research is an attempt to show how cultural information can have a multitude of merits, such as:

- Aiding the students to act and deal with people who are linguistically and culturally different, thus, this will prevent them from culture shock and misconceptions.

- Establishing constructive relationships with individuals from dissimilar backgrounds.

- Helping the learners become more tolerant, respectful, and more empathetic.

- Being able to adapt later to diverse work environments.

It should be noted that learning a foreign language along with intercultural education is paramount for language learners because it exposes them to distinct ways of understanding life, makes them able to absorb diversity, more aware of their own heritage, and cognizant of their acts.

\section{About the authors}

Dr. Fatma ZAGHAR is an associate professor at the University of Oran 2 in Algeria. She obtained a $\mathrm{PhD}$ in Didactics. Her major research themes accentuate Teaching English as a Foreign Language (TEFL), English for Specific Purposes (ESP) Teaching, Intercultural Studies, and Educational Psychology. Currently, she is exploring the fields of Syllabus Design and Educational Technology. https://orcid.org/0000-0003-1077-9719.

Dr. El-Alia Wafaâ ZAGHAR is an associate professor at the University of Oran 2 in Algeria. She holds a PhD in Didactics. Her main areas of interests stress Academic Writing, English for Specific Purposes (ESP), Linguistics, Research Methodology, Teaching English as a Foreign Language (TEFL) and Teacher Education. https://orcid.org/0000-0002-8185-3958. 


\section{References}

Barrett, M. (2008). Intercultural Competences: Reflections based on autobiography of intercultural encounters. Paper presented at the Council of Europe seminar on "Images of the 'Other' in history teaching: The role of history teaching institutions in the north and global south", hosted by the North-South Centre of the Council of Europe, the Ismaili Centre and the Aga Khan Development Network, Lisbon, Portugal, 25th-26th September, $1-8$.

Cushner, K., \& Brislin, R.W. (1996). Intercultural Interaction- A Practical Guide (2 ${ }^{\text {nd }}$ ed.). Sage Publication Inc.

Dervin, F., \& Simpson, A. (2021). Interculturality and the Political within Education. London and New York: Routledge.

Ishihara, N., \& Cohen, A.D. (2021). Teaching and Learning Pragmatics: Where Language and Culture Meet ( $2^{\text {nd }}$ ed.). New York and London: Routledge.

Leeds-Hurwitz, W. (1993). Semiotics and Communication: Signs, codes, cultures. Hillsdale, NJ: Lawrence Erlbaum Associates.

Liddicoat, A., Papademetre, L., Scarino, A., \& Kohler, M. (2003). Report on Intercultural Language Learning. Canberra: Department of Education, Science and Training.

O'Leary, M. (2020). Classroom Observation: A Guide to the Effective Observation of Teaching and Learning. New York: Routledge.

Paige, R.M., Cohen, A.D., Kappler, B., Chi, J.C., \& Lassegard, J.P. (2020). Maximizing Study Abroad: A Students' Guide to Strategies for Language and Culture Learning and Use $\left(2^{\text {nd }}\right.$ ed.). Minneapolis, MN: Center for Advanced Research on Language Acquisition, University of Minnesota.

Richards, J.C. (2005). Curriculum Development in Language Teaching. New York: Cambridge University Press.

Samovar, L.A., Porter, R.E., \& Jain, N.C. (1981). Understanding Intercultural Communication. Belmont, CA: Wadsworth.

Toyoda, E. (2016). Intercultural Knowledge, Awareness and Skills Observed in a Foreign Language Classroom. Intercultural Education, 27 (6), 505-516. 